\title{
Mid-upper arm circumference cut-offs for screening thinness and severe thinness in Indian adolescent girls aged 10-19 years in field settings
}

\author{
Vani Sethi ${ }^{1, *}$, Neha Gupta ${ }^{2}$, Sarang Pedgaonkar ${ }^{2}$, Abhishek Saraswat ${ }^{2}$, \\ Konsam Dinachandra Singh ${ }^{2}$, Hifz Ur Rahman ${ }^{2}$, Arjan de Wagt ${ }^{1}$ and \\ Sayeed Unisa ${ }^{2}$ \\ 'UNICEF, India Country Office, UNICEF House, 73 Lodi Estate, New Delhi - 1 10002, India: ${ }^{2}$ Department of \\ Mathematical Demography and Statistics, International Institute of Population Sciences, Mumbai, India
}

Submitted 28 June 2018: Final revision received 18 January 2019: Accepted 1 February 2019; First published online 21 May 2019

\begin{abstract}
Objective: (i) To assess diagnostic accuracy of mid-upper arm circumference (MUAC) for screening thinness and severe thinness in Indian adolescent girls aged 10-14 and 15-19 years compared with BMI-for-age $Z$-score (BAZ) $<-2$ and $<-3$ as the gold standard and (ii) to identify appropriate MUAC cut-offs for screening thinness and severe thinness in Indian girls aged 10-14 and 15-19 years.

Design: Cross-sectional, conducted October 2016-April 2017.

Setting: Four tribal blocks of two eastern India states, Chhattisgarh and Odisha.

Participants: Girls ( $n$ 4628) aged 10-19 years. Measurements included height, weight and MUAC to calculate BAZ. Standard diagnostic accuracy tests, receiver-operating characteristic curves and Youden index helped arrive at MUAC cut-offs at BAZ $<-2$ and $<-3$, as gold standard.

Results: Mean MUAC and BMI correlation was positive $(0 \cdot 78, P=0.001$ and $r^{2}=0 \cdot 61$ ). Among 10-14 years, MUAC cut-off corresponding to BAZ $<-2$ and $\mathrm{BAZ}<-3$ was $\leq 19.4$ and $\leq 18.9 \mathrm{~cm}$. Among 15-19 years, corresponding values were $\leq 21.6$ and $\leq 20.7 \mathrm{~cm}$. For both $\mathrm{BAZ}<-2$ and $\mathrm{BAZ}<-3$, specificity was higher in 15-19 v. 10-14 years. State-wise variations existed. MUAC cut-offs ranged from $17.7 \mathrm{~cm}$ (10 years) to $22.5 \mathrm{~cm}$ (19 years) for BAZ $<-2$, and from $17.0 \mathrm{~cm}$ (10 years) to $21.5 \mathrm{~cm}$ (19 years) for BAZ $<-3$. Single-age area under the curve range was $0 \cdot 82-0 \cdot 97$.

Conclusions: Study provides a case for use of year-wise and sex-wise contextspecific MUAC-cut-offs for screening thinness/severe thinness in adolescents, rather than one MUAC cut-off across 10-19 years, depending on purpose and logistic constraints.
\end{abstract}

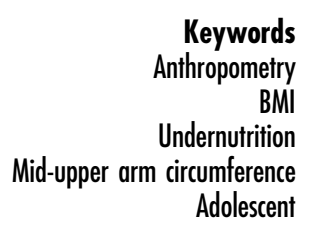

The WHO recommends a BMI-for-age $Z$-score (BAZ) of $<-2$ and $<-3$, respectively, for classifying thinness and severe thinness in adolescents aged $10-19$ years $^{(1)}$. In field settings which are remote or where availability of resources (skilled manpower and financial resources) is a challenge, mid-upper arm circumference (MUAC) has also been used as a field-friendly alternative for screening thinness in adolescents (Table 1$)^{(2-9)}$.

According to the WHO's IMAI (Integrated Management of Adolescent and Adult Illness) hospital care for adolescents and adults guidelines for the

management of illnesses with limited resources, adolescents can be classified as having severe malnutrition ('severe undernutrition') if they have MUAC $<160 \mathrm{~mm}$ or MUAC $=161-185 \mathrm{~mm}$ plus one of the following: pitting oedema up to the knees on both sides, or cannot stand, or sunken eyes ${ }^{(2)}$. Several countries have adopted their country-specific cut-offs (Table 1). India's National Nutrition Support for Tuberculosis programme uses an MUAC cut-off of $<160 \mathrm{~mm}$ for classifying severe thinness in adolescents and determining those eligible for inpatient nutrition rehabilitation and support ${ }^{(8)}$.

*Corresponding author: Email vsethi@unicef.org

(C) The Authors 2019. This is an Open Access article, distributed under the terms of the Creative Commons Attribution licence (http:// creativecommons.org/licenses/by/4.0/), which permits unrestricted re-use, distribution, and reproduction in any medium, provided the original work is properly cited. 
Table 1 Sample country-specific mid-upper arm circumference (MUAC) cut-offs for adolescents for screening severe thinness

\begin{tabular}{|c|c|c|c|c|c|}
\hline Author, year & Country & Age (years) & MUAC cut-off $(\mathrm{cm})$ & Results & Reference \\
\hline WHO, 2011 & - & - & $<16 \cdot 0$ & $\begin{array}{l}\text { Admission criteria for therapeutic } \\
\text { feeding }\end{array}$ & 2 \\
\hline $\begin{array}{l}\text { National CMAM guidelines, } \\
\text { Sudan, } 2017\end{array}$ & $\begin{array}{l}\text { Sudan, } \\
\text { South Sudan }\end{array}$ & $10-18$ & $<16 \cdot 0$ & $\begin{array}{l}\text { Admission criteria for therapeutic } \\
\text { feeding }\end{array}$ & 3 \\
\hline $\begin{array}{l}\text { National CMAM guidelines, } \\
\text { Somalia, } 2010\end{array}$ & Somalia & $10-18$ & $<16 \cdot 0$ & $\begin{array}{l}\text { Admission criteria for therapeutic } \\
\text { feeding }\end{array}$ & 4 \\
\hline $\begin{array}{l}\text { National CMAM guidelines, } \\
\text { Ethiopia, } 2007\end{array}$ & Ethiopia & $\begin{array}{l}6 \text { months-18 } \\
\text { years }\end{array}$ & $<11.0$ & $\begin{array}{l}\text { Admission criteria for therapeutic } \\
\text { feeding }\end{array}$ & 5 \\
\hline Bahwere, 2017 & Syria & $\begin{array}{c}10-14 \\
15-17 \\
\geq 18\end{array}$ & $\begin{array}{l}<16 \cdot 0 \\
<20 \cdot 0 \\
<22 \cdot 0\end{array}$ & $\begin{array}{l}\text { Admission criteria for therapeutic } \\
\text { feeding }\end{array}$ & 6 \\
\hline Martin et al., 2009 & $\begin{array}{l}\text { Western } \\
\text { Australia }\end{array}$ & $12-17$ & $<20 \cdot 0$ & $\begin{array}{l}\text { For initiation for special nutrition } \\
\text { care }\end{array}$ & 7 \\
\hline MoHFW, 2017 & India & $10-18$ & $<16 \cdot 0$ & For nutrition support & 8 \\
\hline FANTA, 2018 & $\begin{array}{l}\text { From a sample } \\
\text { of countries }\end{array}$ & $10-14$ & $<16 \cdot 0$ & $\begin{array}{l}<16.0 \mathrm{~cm}: \text { SAM } \\
\geq 16.0 \text { to }<18.5 \mathrm{~cm}: \text { MAM } \\
\geq 18.5 \mathrm{~cm}: \text { normal }\end{array}$ & 9 \\
\hline FANTA, 2018 & DRC & $10-14$ & $<16 \cdot 0$ & For detecting SAM & 9 \\
\hline FANTA, 2018 & Malawi & $\begin{array}{l}10-11 \\
12-14 \\
15-18\end{array}$ & $\begin{array}{l}<16.0 \\
<16.0 \\
<18.5\end{array}$ & For detecting SAM & 9 \\
\hline FANTA, 2018 & Mozambique & $\begin{array}{l}11-14 \\
15-18\end{array}$ & $\begin{array}{l}<16 \cdot 0 \\
<21 \cdot 0\end{array}$ & For detecting SAM & 9 \\
\hline FANTA, 2018 & Namibia & $10-14$ & $<16 \cdot 0$ & For detecting SAM & 9 \\
\hline FANTA, 2018 & Tanzania & $\begin{array}{c}10-14 \\
\geq 15\end{array}$ & $\begin{array}{l}<16.0 \\
<18.5\end{array}$ & For detecting SAM & 9 \\
\hline FANTA, 2018 & Uganda & $\begin{array}{l}10-14 \\
15-17\end{array}$ & $\begin{array}{l}<16 \cdot 0 \\
<18 \cdot 5\end{array}$ & For detecting SAM & 9 \\
\hline FANTA, 2018 & Zambia & $\begin{array}{l}10-14 \\
15-17\end{array}$ & $\begin{array}{l}<16.0 \\
<18.5\end{array}$ & For detecting SAM & 9 \\
\hline
\end{tabular}

CMAM, community management of acute malnutrition; MoHFW, Ministry of Health and Family Welfare, FANTA, Food and Nutrition Technical Assistance Project; DRC, Democratic Republic of Congo; SAM, severe acute malnutrition; MAM, moderate acute malnutrition.

India is home to approximately 120 million adolescent girls, or about $20 \%$ of the world's population of adolescent girls aged 10-19 years ${ }^{(10)}$. According to an analysis of a 2015-16 nationally representative survey, $10 \cdot 6 \%$ of Indian unmarried girls aged $15-19$ years are thin $(B A Z<-2)$ and $1.8 \%$ are severely thin $(\mathrm{BAZ}<-3$; International Institute for Population Sciences and UNICEF India, unpublished results). India's national health programmes have provision for routine nutrition screening for adolescents through utilizing schools and outreach adolescent village health days ${ }^{(11)}$. The WHO (2007) BAZ charts ${ }^{(1)}$ have not been adopted in adolescent health programmes. The nutrition assessment is conducted annually by public health workers, using clinical signs, biochemical indicators $(\mathrm{Hb})$ and anthropometry (weight, height). In resource-poor field settings, availability of standardized well-calibrated equipment to measure weight and height and calculation of BMI/BAZ by field workers in the absence of field charts and/or calculators are often challenging. Once identified as severely thin, at present, there is also no policy for provision of nutrition support owing to a lack of dialogue on types and modalities of nutrition support to severely thin adolescents in school/community settings. Use of MUAC for screening severely thin adolescents followed by medical nutrition therapy is restricted to hospital settings in tuberculosis wards only ${ }^{(8)}$.

In order to use MUAC as a field-friendly proxy for BAZ, there is a need to assess its diagnostic accuracy compared with BAZ, ascertain whether this diagnostic accuracy differs by age or age bracket (early or late adolescents) and initiate a dialogue on modalities and opportunities to provide nutrition support to those severely thin adolescents, as mere screening will not serve the purpose if an intervention is not in place.

We found four India-based studies that compared MUAC measurements in adolescents aged 10-19 years with BMI/BAZ as gold standard (Table 2) ${ }^{(12-15)}$, which showed mean MUAC and mean BMI have a correlation $(r)$ of $0 \cdot 35-0.822(P<0.001)$. Out of four studies, one study that calculated BAZ reported that $M U A C<18.5 \mathrm{~cm}$ and MUAC $<16 \mathrm{~cm}$ were in agreement with BAZ of $<-2$ and $<-3$, respectively ${ }^{(15)}$. However, none of these studies were in community settings or identified year-wise MUAC cutoffs for thinness and severe thinness for Indian adolescent girls aged 10-19 years.

Thus, the present study was conducted in two eastern India states (Chhattisgarh and Odisha) to assess the 
Table 2 Studies on the correlation between mid-upper arm circumference (MUAC) and BMI/BMI-for-age Z-score (BAZ) in India

\begin{tabular}{|c|c|c|c|c|c|}
\hline Author, year & Location & $\begin{array}{c}\text { Age } \\
\text { (years) }\end{array}$ & $\begin{array}{l}\text { Sample } \\
\text { size }\end{array}$ & Results & Reference \\
\hline $\begin{array}{l}\text { Dasgupta } \\
\text { et al., } 2010\end{array}$ & Kolkata & $10-19$ & 194 & $\begin{array}{l}\text { Burden of thinness: } 60 \cdot 30 \%(\mathrm{MUAC}<5 \text { th percentile) and } \\
47.9 \%(\mathrm{BMI}<5 \text { th percentile). } \\
\text { Strong correlation between measurements of MUAC and } \\
\text { BMI }(r=0.822, \mathrm{SE}=0.035,95 \% \mathrm{Cl} 0.8045,0.8395, P=0.000000 \text {, } \\
\left.r^{2}=0.74\right) . \text { MUAC as a marker was } 94.6 \% \text { sensitive and } 71.2 \% \\
\text { specific }\end{array}$ & 12 \\
\hline $\begin{array}{l}\text { De Kankana, } \\
2016\end{array}$ & $\begin{array}{l}\text { Paschim } \\
\text { Medinipur }\end{array}$ & $10-19$ & 1009 & $\begin{array}{l}\text { Burden of thinness: } 40 \% \text { (MUAC) and } 24 \%(B M I) \\
\text { BMI and MUAC showed significant correlation }(r=0.350, P=0.000) \\
\text { MUAC }<22.9 \mathrm{~cm} \text { showed: SN }=53.4 \%, S P=79.9 \%, P P V=80.0 \% \\
\text { and NPV }=53.6 \%\end{array}$ & 13 \\
\hline $\begin{array}{l}\text { Jeyakumar } \\
\text { et al., } 2013\end{array}$ & $\begin{array}{l}\text { Pune, } \\
\text { Maharashtra }\end{array}$ & $16-18$ & 565 & $\begin{array}{l}\text { Burden of thinness: } 5.0 \%(\text { MUAC }<5 \text { th percentile) and } 4.8 \% \\
\quad(B M I<5 \text { th percentile) } \\
\text { BMI highly correlated with MUAC }(r=0.593) \\
\text { MUAC as a screening tool showed } S N=28.57 \% \text { and SP }=96.46 \%\end{array}$ & 14 \\
\hline $\begin{array}{l}\text { Gupta et al., } \\
2016\end{array}$ & $\begin{array}{l}\text { Delhi and } \\
\text { Haryana }\end{array}$ & $10-19$ & 4183 & $\begin{array}{l}\text { Power of association }(r) \text { between MUAC }(\mathrm{cm}) \text { and BAZ was } 0.68 \\
(P<0.001) . \text { MUAC }<18.5 \mathrm{~cm} \text { was in agreement with BAZ }<-2 \\
(\kappa=0.34 ; 95 \% \mathrm{Cl} 0.31,0.38) \text {. With } \mathrm{BAZ}<-2 \text { as gold standard, } \\
\text { SN and SP of MUAC }<18.5 \mathrm{~cm} \text { was } 73 \text { and } 79 \% \text {, respectively } \\
\text { MUAC }<16 \mathrm{~cm} \text { was compared with } \mathrm{BAZ}<-3 \text { as gold standard and } \\
\text { showed agreement }(\kappa=0.38 ; 95 \% \mathrm{Cl} 0.31,0.38) \text {. SN and SP of } \\
\text { MUAC }<16 \mathrm{~cm} \text { was } 62.6 \text { and } 97.3 \% \text {, respectively }\end{array}$ & 15 \\
\hline
\end{tabular}

SN, sensitivity; SP, specificity; PPV, positive predictive value; NPV, negative predictive value.

diagnostic accuracy of MUAC compared with BAZ and to provide MUAC cut-offs for screening thinness and severe thinness in adolescent girls, by year and age group (10-14 and 15-19 years). We consider this as a first step towards opening a dialogue on the need for simplified year-wise MUAC field charts for screening of severe thinness in Indian adolescents and thereafter arriving at protocols for management of severe thinness in Indian adolescents as part of adolescent health programmes.

\section{Methodology}

\section{Data collection}

We conducted a cross-sectional study on adolescent girls aged 10-19 years in tribal-dominated districts of Odisha (Koraput and Angul districts) and Chhattisgarh (Bastar district) between October 2016 and April 2017. Overall, in these states, $\sim 8 \%$ of adolescent girls aged 15-19 years have BAZ $<-2(7.8 \%$ in Chhattisgarh and $7.7 \%$ in Odisha $)$ as per an analysis of the Fourth Round of the National Family Health Survey (International Institute for Population Sciences and UNICEF India, unpublished results). Our cross-sectional study was a part of a baseline survey for the evaluation of Swabhimaan (meaning 'self-respect' or 'self-pride'), an integrated multisectoral strategy to improve girls' and women's nutrition before conception, during pregnancy and after birth. Swabhimaan is a collaboration between UNICEF and the State Rural Livelihood Missions of Chhattisgarh and Odisha. A description of the Swabhimaan strategy and its impact evaluation design is available elsewhere ${ }^{(16)}$
The location and sample size for our cross-sectional study were guided by the design of the Swabhimaan strategy, outcome indicators and the change envisaged. Location was four tribal-dominated blocks: Bastar and Bakawand (Bastar district), Pallara (Angul district) and Koraput Sadar (Koraput district). The eligible participants were non-married and nonpregnant adolescent girls aged 10-19 years residing in the study areas. The sample size of eligible participants to be covered was estimated at 3256 adolescent girls (2196 in Chhattisgarh and 1060 in Odisha). Temporary residents, i.e. those adolescents present in homes at the time of the house-to-house census but who said they would migrate within two months of the census, were excluded. Married and/or pregnant adolescent girls, included in other surveys, were also excluded as all variables considered in the current analysis were not available for them. The target sample was collected using simple random sampling. Although we estimated a sample size of 3256 adolescent girls as eligible participants, we interviewed a total of 4648 eligible participants (2921 in Chhattisgarh and 1727 in Odisha). Of the total of 4648 eligible participants interviewed, fourteen adolescents were not given anthropometric measurements and six adolescents' BAZ was flagged, therefore 4628 adolescent girls were included in the analysis.

Data collection was carried out by thirty investigators, who were supervised by six supervisors. Paper-based method for data collection was used. Written informed consent was obtained from all participants over 18 years of age. For those under 18 years, written consent was taken from their parent(s) or guardian(s) and verbal consent was also taken from the respondents. Utmost confidentiality of information and anonymity of respondents was ensured to prevent linking to any individual. All interviewers 
participated in a standardization exercise in which they took repeated measurements of ten adolescents in three teams of ten interviewers each. Each interviewer took two height, weight and MUAC measurements for ten participants. We then compared these with supervisors' $(n 6)$ measurements, as well as within teams. The technical error of measurement ${ }^{(17)}$ for weight was 0.99 and for height was 0.95. Supervisors conducted back-checks for $10 \%$ of interviews.

Ethical approval was obtained from the Institutional Ethics Committees of the All India Institute of Medical Sciences in Chhattisgarh and Odisha. The impact evaluation has been registered with the Registry for International Development Impact Evaluations (RIDIE-STUDY-ID58261b2f46876) ${ }^{(16)}$.

A common interview on sociodemographic and household characteristics was administered to all adolescents' guardians using a pre-tested, structured, bilingual questionnaire (English and Hindi in Chhattisgarh; English and Odia in Odisha). The adolescent girls' interviews covered sociodemographics and anthropometric measurements (weight, height and MUAC). Anthropometric measurements were conducted using standard techniques ${ }^{(18)}$. Weight to the nearest $0 \cdot 1 \mathrm{~kg}$ was recorded using a SECA electronic weighing scale with minimal clothing. Height was taken barefoot to the nearest $0 \cdot 1 \mathrm{~cm}$ using a stadiometer. MUAC was measured to the nearest $0 \cdot 1 \mathrm{~cm}$ with a non-stretchable measuring tape (procured from UNICEF supply department). The tape was placed firmly but gently on the arm to avoid compression of soft tissue. The weighing scales and stadiometer were calibrated on a weekly basis prior to data collection with standard weights (1, 2 and $5 \mathrm{~kg})$ and a metre rod $(100 \mathrm{~cm})$. The mean SE of measurements for height, weight and MUAC across all the data collection teams were insignificant and ranged between 0.001 and 0.025 (95\% CI $-0.004,0.042 ; P<0.10)$. The non-response rate was negligible (Chhattisgarh $0.3 \%$; Odisha $0 \cdot 4 \%$ ). BAZ was calculated using the WHO reference (Stata macro) and classified as $<-3$ (severe thinness) and $<-2$ (thinness) ${ }^{(1)}$.

\section{Statistical methods}

Primary data were entered in CS-Pro version 4.1. Descriptive statistics were generated using the statistical software package IBM SPSS Statistics version 20. MUAC cut-offs for screening thinness and severe thinness and year-wise MUAC cut-offs, as well as those for younger (10-14 years) and older (15-19 years) adolescents, were determined using $\mathrm{BAZ}<-2$ and $\mathrm{BAZ}<-3$, respectively, as the gold standard.

Diagnostic accuracy of MUAC compared with BAZ was assessed using sensitivity (SN), specificity (SP), negative predictive value (NPV) and positive predictive value (PPV), whose values were calculated using the proportion of true positives (TP), false positives (FP), true negatives (TN) and false negatives (FN) using a $2 \times 2$ table as shown below:

\begin{tabular}{lll}
\hline \multirow{2}{*}{$\begin{array}{l}\text { Thin according to MUAC } \\
\text { cut-offs generated in } \\
\text { the paper }\end{array}$} & \multicolumn{2}{c}{$\begin{array}{c}\text { Thin according } \\
\text { to BAZ }\end{array}$} \\
\cline { 2 - 3 } \cline { 2 - 3 } & Yes & No \\
\hline Yes & TP & FP \\
No & FN & TN \\
\hline
\end{tabular}

SN measures the percentage of true positives (thin/severely thin adolescents) calculated as $\mathrm{TP} /(\mathrm{TP}+\mathrm{FN})$; SP measures the percentage of true negatives (not thin/severely thin adolescents) calculated as $\mathrm{TN} /(\mathrm{TN}+\mathrm{FP}) ; \mathrm{NPV}$ tells us how likely an adolescent is to not be thin if the test is negative, calculated as TN/(TN $+\mathrm{FN})$; and PPV tells us how likely an adolescent is to be thin if the test is positive, calculated as $\mathrm{TP} /(\mathrm{TP}+\mathrm{FP})$. $\mathrm{FP}(\%)$ is calculated as $\mathrm{FP} /(\mathrm{FP}+\mathrm{TP})$ and $\mathrm{FN}(\%)$ is calculated as $\mathrm{FN} /(\mathrm{TN}+\mathrm{FN})$. Unlike SN and SP, the NPV and PPV are largely dependent on disease prevalence in an examined population. Values of SN, SP, PPV and NPV were calculated for MUAC cut-offs points against $\mathrm{BAZ}<-2$ and $\mathrm{BAZ}<-3$.

Receiver-operating characteristic (ROC) curve analysis was undertaken to determine the area under the curve (AUC), along with its $95 \% \mathrm{CI}$, to establish the optimal cut-off values of MUAC to identify thinness and severe thinness. The shape of the ROC curve and the AUC determine how high is the discriminative power of a test. The AUC can have any value between 0 and 1 and it is a good indicator of the goodness of the test. The categories used to summarize accuracy of AUC in ROC curve analysis are as follows: excellent (0.9-1.0), good $(0 \cdot 8-0 \cdot 9)$, fair $(0 \cdot 7-0 \cdot 8)$, poor $(0 \cdot 6-0 \cdot 7)$ and fail $(0 \cdot 5-0 \cdot 1)$. A test with AUC $\geq 0.85$ is considered an accurate test ${ }^{(19)}$. Although AUC gives an overall picture of the behaviour of a diagnostic test across all cutoff values, there remains a necessity to ascertain the specific cut-off value that could be used for screening and for this purpose Youden's index (YI) is used ${ }^{(20)}$. The YI is equivalent to the AUC subtended by a single operating point in the ROC curve ${ }^{(21)}$. We calculated YI by deducting 1 from the sum of the test's SN and SP expressed not as a percentage but as part of a whole number: $(\mathrm{SN}+\mathrm{SP})-1$. It is one of the oldest measures for diagnostic accuracy, being used for the evaluation of overall discriminative power of a diagnostic procedure and for comparison of this test with other tests $^{(22)}$. For a test with poor diagnostic accuracy, YI equals 0 , and in a perfect test YI equals 1 . The YI was calculated using MedCalc software version 17.9.7. Single-age MUAC cut-offs as well as MUAC cut-offs for the groups of younger (10-14 years) and older adolescents (15-19 years) at $\mathrm{BAZ}<-2$ and $\mathrm{BAZ}<-3$ were determined on the basis of the highest corresponding value of YI.

\section{Results}

The analytical sample comprised 4628 adolescents (2910 were from Chhattisgarh and 1718 from Odisha). 
Table 3 Sociodemographic characteristics of the sample of adolescent girls aged 10-19 years ( $n$ 4628) from two eastern India states (Chhattisgarh and Odisha), October 2016-April 2017

\begin{tabular}{|c|c|c|c|c|c|c|c|c|c|c|c|c|}
\hline \multirow[b]{3}{*}{ Characteristic } & \multirow{2}{*}{\multicolumn{2}{|c|}{$\begin{array}{l}\text { Chhattisgarh } \\
\text { (n 2920) }\end{array}$}} & \multirow{2}{*}{\multicolumn{2}{|c|}{$\begin{array}{l}\text { Odisha } \\
(n \text { 1728) }\end{array}$}} & \multirow[b]{3}{*}{$n$} & \multicolumn{5}{|c|}{ Pooled ( $n$ 4628) } & & \\
\hline & & & & & & \multirow[b]{2}{*}{$\%$} & \multicolumn{2}{|c|}{$\operatorname{MUAC}(\mathrm{cm})$} & \multicolumn{2}{|c|}{ BMI $\left(\mathrm{kg} / \mathrm{m}^{2}\right)$} & \multicolumn{2}{|c|}{ BAZ } \\
\hline & $n$ & $\%$ & $n$ & $\%$ & & & Mean & SD & Mean & SD & Mean & SD \\
\hline \multicolumn{13}{|l|}{ Age (years) } \\
\hline 10 & 186 & $6 \cdot 4$ & 147 & $8 \cdot 6$ & 333 & $7 \cdot 2$ & $18 \cdot 7$ & $2 \cdot 42$ & $15 \cdot 3$ & $2 \cdot 98$ & $-1 \cdot 0$ & $1 \cdot 28$ \\
\hline 11 & 307 & $10 \cdot 6$ & 181 & $10 \cdot 5$ & 488 & 10.5 & $19 \cdot 2$ & $2 \cdot 19$ & $15 \cdot 4$ & 2.09 & $-1 \cdot 1$ & $1 \cdot 14$ \\
\hline 12 & 355 & $12 \cdot 2$ & 179 & $10 \cdot 4$ & 534 & 11.5 & $20 \cdot 3$ & $2 \cdot 34$ & $16 \cdot 1$ & $2 \cdot 12$ & $-1 \cdot 1$ & $1 \cdot 11$ \\
\hline 13 & 371 & $12 \cdot 8$ & 175 & $10 \cdot 2$ & 546 & 11.8 & 21.5 & $2 \cdot 67$ & $17 \cdot 1$ & $2 \cdot 16$ & -0.9 & 1.06 \\
\hline 14 & 394 & 13.5 & 197 & 11.5 & 591 & $12 \cdot 8$ & $22 \cdot 3$ & $2 \cdot 25$ & $17 \cdot 8$ & $2 \cdot 33$ & -0.9 & 1.04 \\
\hline 15 & 325 & $11 \cdot 2$ & 190 & $11 \cdot 1$ & 515 & $11 \cdot 1$ & $22 \cdot 9$ & $2 \cdot 12$ & $18 \cdot 2$ & $2 \cdot 07$ & -0.9 & 0.91 \\
\hline 16 & 323 & $11 \cdot 1$ & 193 & $11 \cdot 2$ & 516 & $11 \cdot 2$ & 23.5 & 2.09 & $18 \cdot 8$ & $2 \cdot 12$ & -0.8 & 0.85 \\
\hline 17 & 308 & $10 \cdot 6$ & 196 & 11.4 & 504 & $10 \cdot 9$ & $23 \cdot 6$ & $2 \cdot 23$ & $18 \cdot 7$ & $2 \cdot 01$ & $-1 \cdot 0$ & 0.88 \\
\hline 18 & 294 & $10 \cdot 1$ & 178 & $10 \cdot 4$ & 472 & $10 \cdot 2$ & $23 \cdot 8$ & 1.98 & $18 \cdot 9$ & 2.06 & -0.9 & 0.81 \\
\hline 19 & 47 & 1.6 & 82 & $4 \cdot 8$ & 129 & $2 \cdot 8$ & $23 \cdot 9$ & $2 \cdot 36$ & $18 \cdot 6$ & $2 \cdot 15$ & $-1 \cdot 1$ & 0.90 \\
\hline \multicolumn{13}{|l|}{ Age group (years) } \\
\hline $10-14$ & 1613 & $55 \cdot 4$ & 879 & $51 \cdot 2$ & 2492 & 53.9 & $20 \cdot 6$ & $2 \cdot 71$ & $16 \cdot 5$ & $2 \cdot 49$ & $-1 \cdot 0$ & $1 \cdot 12$ \\
\hline $15-19$ & 1297 & $44 \cdot 6$ & 839 & $48 \cdot 8$ & 2136 & $46 \cdot 2$ & 23.5 & $2 \cdot 15$ & $18 \cdot 6$ & 2.09 & -0.9 & 0.87 \\
\hline \multicolumn{13}{|l|}{ Religion } \\
\hline Hindu & 2859 & $98 \cdot 3$ & 1637 & $95 \cdot 3$ & 4496 & $97 \cdot 2$ & \multicolumn{2}{|c|}{-} & \multicolumn{2}{|c|}{-} & \multicolumn{2}{|c|}{ - } \\
\hline Non-Hindu & 51 & 1.8 & 81 & 4.7 & 132 & $2 \cdot 9$ & \multicolumn{2}{|c|}{-} & \multicolumn{2}{|c|}{-} & \multicolumn{2}{|c|}{-} \\
\hline \multicolumn{13}{|l|}{ Caste } \\
\hline Scheduled caste & 70 & $2 \cdot 4$ & 266 & $15 \cdot 5$ & 336 & $7 \cdot 3$ & \multicolumn{2}{|c|}{-} & \multicolumn{2}{|c|}{-} & \multicolumn{2}{|c|}{-} \\
\hline Scheduled tribe & 1895 & $65 \cdot 1$ & 928 & $54 \cdot 0$ & 2823 & $61 \cdot 0$ & \multicolumn{2}{|c|}{-} & \multicolumn{2}{|c|}{-} & \multicolumn{2}{|c|}{-} \\
\hline Other backward caste & 811 & $27 \cdot 9$ & 389 & $22 \cdot 6$ & 1200 & $25 \cdot 9$ & \multicolumn{2}{|c|}{-} & \multicolumn{2}{|c|}{-} & \multicolumn{2}{|c|}{-} \\
\hline General & 134 & 4.6 & 135 & 7.9 & 269 & $5 \cdot 8$ & & & & - & & \\
\hline Currently attending schoc & & & & & & & & & & & & \\
\hline Yes & 2179 & 74.9 & 2179 & 74.9 & 3165 & 68.4 & & & & - & & \\
\hline No & 688 & 23.6 & 688 & $23 \cdot 6$ & 1267 & $27 \cdot 4$ & & & & - & & \\
\hline Never gone to school & 43 & 1.5 & 43 & 1.5 & 196 & $4 \cdot 2$ & & & & - & & \\
\hline
\end{tabular}

MUAC, mid-upper arm circumference; BAZ, BMI-for-age Z-score.

Their mean age was 14.26 (SD 2.55) years. Sociodemographic characteristics of the participants are described in Table 3. Only $68 \%$ reported being currently enrolled in school. Nearly all (97.2\%) participants belonged to the Hindu religion. Caste-wise, $94 \%$ of participants were from backward castes.

Mean BMI of the adolescent girls aged 10-14 and 15-19 years was $16.5(\mathrm{sD} 2.5)$ and $18.6(\mathrm{sD} 2.1) \mathrm{kg} / \mathrm{m}^{2}$, respectively. Corresponding figures for mean $\mathrm{BAZ}$ were -1.0 (SD 1.12) and -0.9 (SD 0.87), and those for MUAC were $20 \cdot 6(\mathrm{sD} 2 \cdot 7) \mathrm{cm}$ and $23.5(\mathrm{SD} 2 \cdot 2) \mathrm{cm}$.

\section{Correlation between BMI and mid-upper arm circumference}

Figure 1 shows the correlation between BMI and MUAC in the pooled data as well as for Chhattisgarh and Odisha, separately. A significant positive correlation was found between measurements of MUAC and BMI $(r=0.78$, $P=0.001, r^{2}=0.61$ ), whereas in state-wise correlation, higher correlation was obtained for Chhattisgarh $(r=0.82, P=0.001)$ than for Odisha $(r=0.77, P=0.001)$. In the age-wise correlation, the lowest correlation was found at 10 years of age $(r=0.41, P=0.001)$ and the highest at 15 years $(r=0.81, P=0.001)$, with all other correlations lying between 0.63 and $0.79(P=0.001)$.

\section{Diagnostic accuracy of mid-upper arm circumference cut-offs for thinness and severe thinness}

Table 4 summarizes the MUAC cut-offs for BAZ $<-2$. The optimal MUAC cut-off to detect thinness among girls aged 10-14 years was $\leq 19.4 \mathrm{~cm} \quad(\mathrm{SN}=84.0 \%$, $\mathrm{SP}=75.4 \%)$ and among older adolescents it was $\leq 21.6 \mathrm{~cm} \quad(\mathrm{SN}=81.4 \%, \mathrm{SP}=87.1 \%)$. Single-age MUAC cut-offs in adolescent girls ranged between $17.7 \mathrm{~cm}$ (10 years) and $22.5 \mathrm{~cm}$ (19 years) for identifying thinness (BAZ <-2). Overall, the optimal MUAC cut-off for screening thinness among adolescent girls aged 10-19 years was $\leq 20.9 \mathrm{~cm} \quad(\mathrm{YI}=0.56, \mathrm{SN}=83.3-86 \cdot 1 \%, \mathrm{SP}=70 \cdot 3-72 \cdot 8 \%$, AUC $=0.85-0.86, P=0.001)$. Comparing state-wise, the optimal MUAC cut-off for screening thinness among adolescent girls aged $10-19$ years was $\leq 20.9 \mathrm{~cm}$ in Chhattisgarh and $\leq 21.3 \mathrm{~cm}$ in Odisha (data not shown). The SN and SP of all the single-age MUAC cut-offs ranged from 70 to $90 \%$ depending on the true positives and true negatives that the age-specific cut-offs could identify. The AUC ranged from 0.84 to $0.94(P=0.001)$, signifying good/excellent diagnostic power of the identified single-age cut-offs. At all single-age MUAC cut-offs, the NPV was much higher than the PPV, signifying that the MUAC cut-offs were able to correctly exclude adolescents without thinness. We also did an additional analysis where we obtained the single-age 


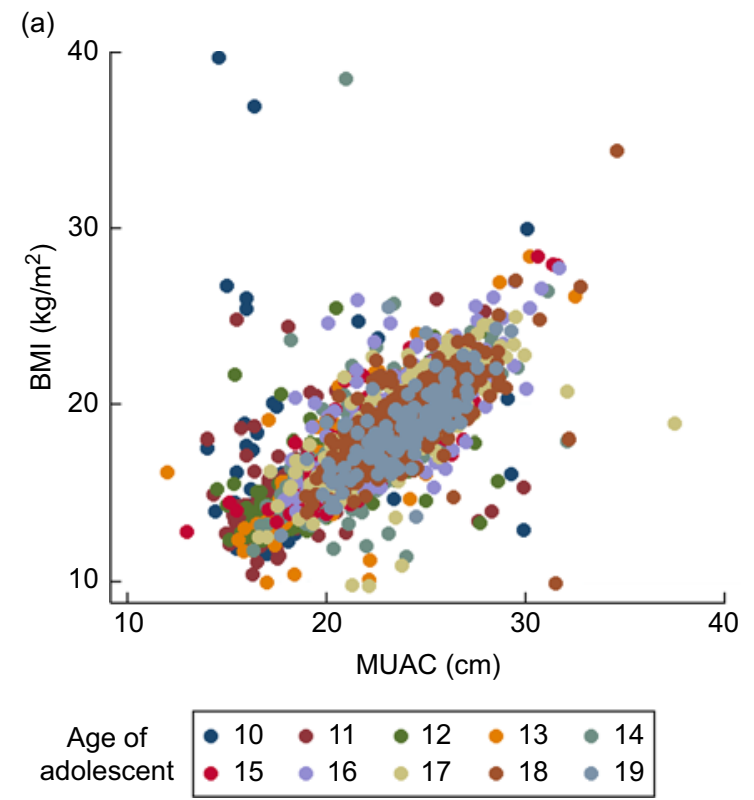

(b)

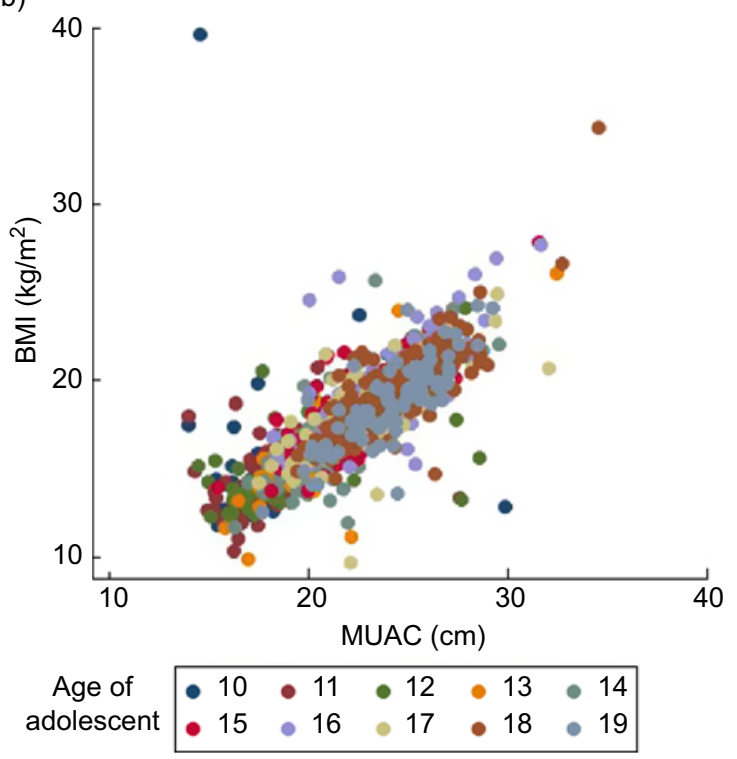

(c)

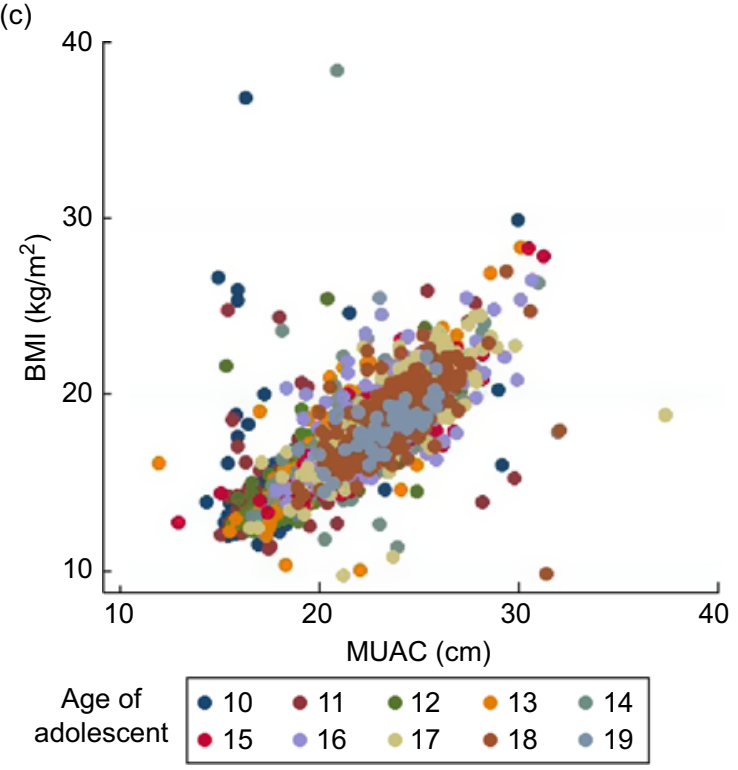

\begin{tabular}{|l|c|c|c|c|c|c|c|c|c|c|}
\hline Age of adolescent (years) & 10 & 11 & 12 & 13 & 14 & 15 & 16 & 17 & 18 & 19 \\
\hline Correlation coefficient $(r)$ & 0.41 & 0.70 & $0 \cdot 79$ & 0.63 & 0.72 & 0.81 & 0.72 & 0.75 & $0 \cdot 73$ & $0 \cdot 74$ \\
\hline
\end{tabular}

Fig. 1 Scatter plots showing the correlation between BMI and mid-upper arm circumference (MUAC), overall and by state, in adolescent girls aged 10-19 years $(n$ 4628) from two eastern India states, October 2016-April 2017: (a) pooled (correlation coefficient $(r)=0.78, P=0.001)$; (b) Chhattisgarh $(r=0.82, P=0.001)$; (c) Odisha $(r=0.77, P=0.001)$

and grouped cut-offs for moderate thinness (BAZ $<-2$ and $\geq-3$; data not shown). There was no significant difference obtained in the cut-offs for thinness and moderate thinness.

Table 5 summarizes the MUAC cut-offs for BAZ $<-3$. Single-age MUAC cut-offs in adolescent girls ranged between $17.0 \mathrm{~cm}$ (10 years) and $21.5 \mathrm{~cm}$ (19 years) for severe thinness $(\mathrm{BAZ}<-3)$. The optimal MUAC cut-off to detect severe thinness among girls aged 10-14 years was $\leq 18.9 \mathrm{~cm}(\mathrm{SN}=84.6 \%, \mathrm{SP}=74.1 \%)$ and among older adolescents it was $\leq 20 \cdot 7 \mathrm{~cm}(\mathrm{SN}=86 \cdot 1 \%$, SP $=93 \cdot 1 \%)$. The SN and SP of the single-age MUAC cut-offs ranged from 70 to $100 \%$. The AUC were in the range of $0 \cdot 84-0.97$, signifying good/excellent diagnostic power of the identified single-age cut-offs. The PPV of the single-age MUAC cutoffs ranged from 8 to $30 \%$, while the NPV was $>99 \%$ for all ages. Thus, the PPV was lower for single-age MUAC cut-offs with BAZ $<-3$ as the gold standard compared with MUAC cut-offs with BAZ $<-2$, while the NPV was 
Table 4 Diagnostic test accuracy measures for varying cut-offs of mid-upper arm circumference (MUAC) for predicting thinness (BMI-for-age $Z$-score $<-2$ as gold standard) among adolescent girls aged $10-19$ years ( $n 4628)$ from two eastern India states (Chhattisgarh and Odisha), October 2016-April 2017

\begin{tabular}{|c|c|c|c|c|c|c|c|c|c|c|}
\hline Age (years) & MUAC cut-off $(\mathrm{cm})$ & SN (\%) & SP (\%) & YI & $\mathrm{FN}(\%)$ & FP (\%) & PPV (\%) & NPV (\%) & $A \cup C$ & $95 \% \mathrm{Cl}$ \\
\hline 10 & $\leq 17 \cdot 7$ & $87 \cdot 3$ & $71 \cdot 1$ & 0.58 & $4 \cdot 0$ & $58 \cdot 6$ & 41.4 & $96 \cdot 0$ & 0.84 & $0.79,0.87$ \\
\hline 11 & $\leq 18 \cdot 1$ & $81 \cdot 6$ & $81 \cdot 2$ & 0.62 & 5.4 & $48 \cdot 0$ & $52 \cdot 0$ & 94.6 & 0.87 & $0.84,0.90$ \\
\hline 12 & $\leq 19 \cdot 0$ & $87 \cdot 3$ & $86 \cdot 0$ & 0.73 & $4 \cdot 1$ & $35 \cdot 8$ & 64.2 & 95.9 & 0.92 & $0.89,0.94$ \\
\hline 13 & $\leq 20 \cdot 1$ & $90 \cdot 0$ & $82 \cdot 4$ & 0.72 & $1 \cdot 7$ & $57 \cdot 2$ & $42 \cdot 8$ & 98.3 & 0.92 & $0.89,0.94$ \\
\hline 14 & $\leq 20.6$ & 77.9 & 85.4 & 0.63 & $3 \cdot 7$ & 55.5 & 44.5 & $96 \cdot 2$ & 0.89 & $0.87,0.92$ \\
\hline 15 & $\leq 20.8$ & 71.6 & 93.9 & 0.65 & $3 \cdot 3$ & 42.5 & 57.5 & $96 \cdot \overline{6}$ & 0.92 & $0.89,0.94$ \\
\hline 16 & $\leq 21.6$ & $79 \cdot 4$ & 88.0 & 0.67 & $1 \cdot 8$ & $64 \cdot 7$ & $35 \cdot 3$ & $98 \cdot 1$ & 0.91 & $0.89,0.94$ \\
\hline 17 & $\leq 21.7$ & 91.3 & $88 \cdot 2$ & 0.79 & 0.9 & $56 \cdot 3$ & 43.7 & $99 \cdot 1$ & 0.94 & $0.92,0.96$ \\
\hline 18 & $\leq 22.3$ & $83 \cdot 6$ & $81 \cdot 3$ & 0.65 & $2 \cdot 2$ & $65 \cdot 8$ & 34.1 & $97 \cdot 8$ & 0.89 & $0.86,0.91$ \\
\hline 19 & $\leq 22.5$ & $72 \cdot 2$ & $82 \cdot 3$ & 0.54 & $5 \cdot 2$ & $60 \cdot 7$ & $39 \cdot 3$ & 94.8 & 0.86 & $0.79,0.92$ \\
\hline $10-14$ & $\leq 19.4$ & $84 \cdot 0$ & 75.4 & 0.59 & $4 \cdot 2$ & 58.7 & 41.3 & $95 \cdot 8$ & 0.86 & $0.84,0.87$ \\
\hline $15-19$ & $\leq 21.6$ & 81.4 & $87 \cdot 1$ & 0.68 & $2 \cdot 2$ & $60 \cdot 0$ & $40 \cdot 0$ & $97 \cdot 8$ & 0.91 & $0.89,0.92$ \\
\hline
\end{tabular}

SN, sensitivity; SP, specificity; YI, Youden index; FN, false negative; FP, false positive; PPV, positive predictive value; NPV, negative predictive value; AUC, area under the (receiver-operating characteristic) curve.

Table 5 Diagnostic test accuracy measures for varying cut-offs of mid-upper arm circumference (MUAC) for predicting severe thinness (BMl-for-age Z-score $<-3$ as gold standard) among adolescent girls aged 10-19 years ( $n$ 4628) from two eastern India states (Chhattisgarh and Odisha), October 2016-April 2017

\begin{tabular}{|c|c|c|c|c|c|c|c|c|c|c|}
\hline Age (years) & MUAC cut-off $(\mathrm{cm})$ & SN (\%) & SP $(\%)$ & $\mathrm{YI}$ & FN (\%) & $\mathrm{FP}(\%)$ & PPV (\%) & NPV (\%) & AUC & $95 \% \mathrm{Cl}$ \\
\hline 10 & $\leq 17 \cdot 0$ & 87.5 & $79 \cdot 6$ & 0.67 & 0.3 & $90 \cdot 4$ & $9 \cdot 6$ & $99 \cdot 7$ & 0.87 & $0.83,0.91$ \\
\hline 11 & $\leq 17.6$ & 94.7 & $79 \cdot 3$ & 0.74 & 0.2 & 84.4 & $15 \cdot 6$ & 99.8 & 0.90 & $0.87,0.92$ \\
\hline 12 & $\leq 18.2$ & $91 \cdot 3$ & 84.5 & 0.75 & 0.4 & 79.0 & $21 \cdot 0$ & 99.6 & 0.94 & $0.91,0.96$ \\
\hline 13 & $\leq 18 \cdot 8$ & 85.0 & $92 \cdot 8$ & 0.77 & $0 \cdot 6$ & $69 \cdot 0$ & $31 \cdot 0$ & 99.4 & 0.91 & $0.88,0.93$ \\
\hline 14 & $\leq 20.3$ & 71.4 & 84.6 & 0.56 & 1.2 & 85.4 & $14 \cdot 6$ & 98.8 & 0.84 & $0.81,0.87$ \\
\hline 15 & $\leq 20 \cdot 3$ & $100 \cdot 0$ & $93 \cdot 4$ & 0.93 & 0.0 & $71 \cdot 7$ & $28 \cdot 3$ & $100 \cdot 0$ & 0.97 & $0.95,0.98$ \\
\hline 16 & $\mathrm{NA}^{*}$ & $\mathrm{NA}^{*}$ & $\mathrm{NA}^{*}$ & $\mathrm{NA}^{*}$ & $\mathrm{NA}^{*}$ & $\mathrm{NA}^{*}$ & $\mathrm{NA}^{*}$ & $\mathrm{NA}^{*}$ & $\mathrm{NA}^{*}$ & $\mathrm{NA}^{*}$ \\
\hline 17 & $\leq 20.7$ & 76.9 & $94 \cdot 1$ & 0.71 & 0.6 & 74.3 & $25 \cdot 7$ & 99.4 & 0.91 & $0.89,0.94$ \\
\hline 18 & $\leq 21 \cdot 1$ & $75 \cdot 0$ & 92.5 & 0.67 & 0.2 & $92 \cdot 1$ & 7.9 & $99 \cdot 8$ & 0.97 & $0.95,0.98$ \\
\hline 19 & $\leq 21.5$ & $80 \cdot 0$ & $87 \cdot 3$ & 0.67 & 0.9 & $80 \cdot 0$ & $20 \cdot 0$ & 99.1 & 0.84 & $0.76,0.90$ \\
\hline $10-14$ & $\leq 18.9$ & 84.6 & $74 \cdot 1$ & 0.58 & 0.7 & $89 \cdot 1$ & 10.9 & 99.3 & 0.86 & $0.83,0.86$ \\
\hline $15-19$ & $\leq 20 \cdot 7$ & $86 \cdot 1$ & 93.1 & 0.79 & 0.2 & $82 \cdot 2$ & $17 \cdot 8$ & $99 \cdot 8$ & 0.93 & $0.92,0.94$ \\
\hline
\end{tabular}

SN, sensitivity; SP, specificity; YI, Youden index; FN, false negative; FP, false positive; PPV, positive predictive value; NPV, negative predictive value; AUC, area under the (receiver-operating characteristic) curve.

*NA = cases insufficient to estimate a reliable MUAC cut-off for severe thinness.

higher. The optimal MUAC cut-off for screening severe thinness among adolescent girls aged 10-19 years was $\leq 19.5 \mathrm{~cm}(\mathrm{YI}=0.52-0.69, \mathrm{SN}=0.63-87.7 \%, \mathrm{SP}=81.3-88.9 \%$, AUC $=0.83-0.90, P=0.001)$. Comparing state-wise, the optimal MUAC cut-off for screening severe thinness among adolescent girls aged 10-19 years was $\leq 19.4 \mathrm{~cm}$ in Chhattisgarh and $\leq 18.5 \mathrm{~cm}$ in Odisha (data not shown).

Each ROC curve shows the trade-off between sensitivity and specificity. The AUC for thinness among girls aged 10-14 and 15-19 years was 0.86 and 0.91 , respectively $(P<0.0001$; Fig. 2). Similarly, the AUC for severe thinness among girls aged $10-14$ and $15-19$ years was 0.86 and 0.93 , respectively $(P<0.0001$; Fig. 3$)$. The AUC values were highly significant and the curves were closer to top left corner, indicating high accuracy of the test to detect thinness and severe thinness.

\section{Prevalence of thinness and severe thinness}

The burden of thinness (BMI $<-2)$ and severe thinness (BMI $<-3$ ) among adolescent girls aged $10-14$ years was $17 \cdot 1$ and $3.6 \%$, respectively. Corresponding figures for adolescent girls aged 15-19 years were 9.6 and $1.7 \%$ (Table 6). By BAZ, the prevalence of thinness and severe thinness was highest among adolescents aged 12 years which counted for 22.6 and $4.5 \%$, respectively; while the lowest prevalence was found in age 16 years where $7.5 \%$ were thin. According to MUAC, the burden of thinness among adolescent girls aged 10-14 years $(M U A C \leq 19.4 \mathrm{~cm})$ and $15-19$ years $(M U A C \leq 21.6 \mathrm{~cm}$ ) was 41.3 and $40.0 \%$, respectively; whereas the burden of severe thinness among adolescent girls aged 10-14 years $(M U A C \leq 18.9 \mathrm{~cm})$ and $15-19$ years $(M U A C \leq 20.7 \mathrm{~cm}$ ) was 11.0 and $17.7 \%$, respectively. The burden of thinness and severe thinness was higher when assessed with MUAC compared with BAZ in both age groups (Table 6).

\section{Discussion}

The present study has several important inferences pertaining to prevalence of thinness and severe thinness in adolescents aged 10-19 years using BAZ and MUAC as well as 
(a)

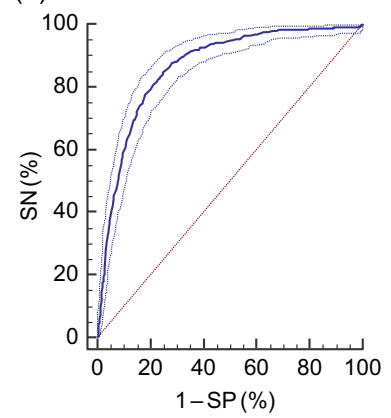

(b)

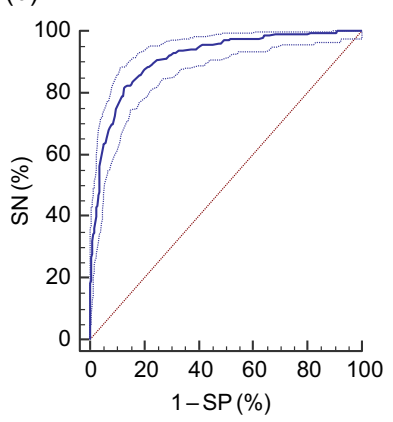

Fig. 2 Receiver-operating characteristic curves $(-)$ of mid-upper arm circumference to identify thinness (BMI Z-score $<-2$ ), by age group, among adolescent girls aged $10-19$ years ( $n$ 4628) from two eastern India states (Chhattisgarh and Odisha), October 2016-April 2017: (a) 10-14 years (sensitivity $(\mathrm{SN})=84.5 \%$; specificity $(\mathrm{SP})=75.1 \%$; criterion $=\leq 19.45 \mathrm{~cm}$; area under the curve (AUC) $=0.863 ; P<0.001)$; (b) 15-19 years $(\mathrm{SN}=82.0 \%$; SP $=87.0 \%$; criterion $=\leq 21.65 \mathrm{~cm} ; \mathrm{AUC}=0.911$; $P<0.001$ ). ( $\quad$ ) represent the $95 \% \mathrm{Cl}$ and $(\longrightarrow)$ represents the line of no discrimination

(a)

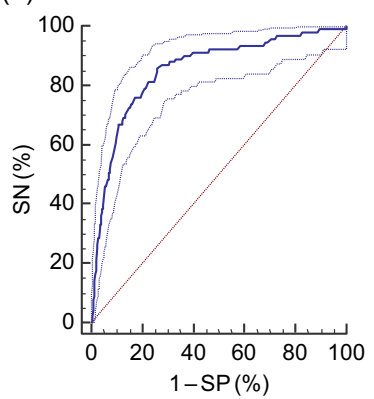

(b)

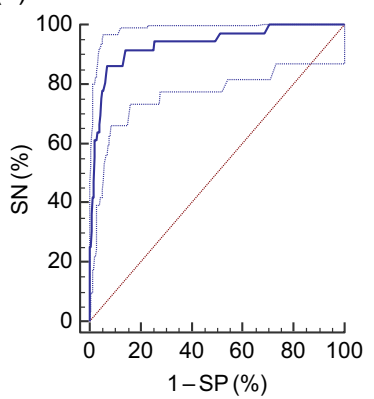

Fig. 3 Receiver-operating characteristic curves (-) of mid-upper arm circumference to identify severe thinness (BMl Z-score <-3), by age group, among adolescent girls aged $10-19$ years $(n 4628)$ in two eastern India states (Chhattisgarh and Odisha), October 2016-April 2017: (a) 10-14 years (sensitivity $(\mathrm{SN})=85.6 \%$; specificity $(\mathrm{SP})=74.1 \%$; criterion $=$ $\leq 18.95 \mathrm{~cm}$; area under the curve $($ AUC $)=0.860 ; P<0.001$ ); (b) $15-19$ years $(\mathrm{SN}=86.1 \% ; \quad \mathrm{SP}=93.1 \%$; criterion = $\leq 20.70 \mathrm{~cm} ; \quad A \cup C=0.934 ; P<0.001) . \quad(\quad)$ represent the $95 \% \mathrm{Cl}$ and $(\quad)$ represents the line of no discrimination

year-wise MUAC cut-offs for screening thinness and severe thinness.

First, the burden of thinness (BAZ <-2) among adolescent girls using identified the MUAC cut-off was fourfold higher compared with BAZ (e.g. MUAC-based 40\%, BAZbased $9.6 \%$, at $15-19$ years). There is limited information from India on use of MUAC for detection of thinness among adolescent girls. Community-based studies reported a burden of thinness among adolescent girls between 24 and $48 \%$ (according to BMI) and between 40 and $60 \%$ (according to MUAC $)^{(12,13)}$. However, one study reported lower burden of thinness as $4.8 \%$ (BMI) and $5.0 \%$ (MUAC), respectively ${ }^{(16)}$.

Second, a significant correlation was found between BAZ and MUAC measurements $(r=0.78, \quad P=0.001$, $\left.r^{2}=0 \cdot 61\right)$. Our study results are comparable with all three

studies which also reported a significant correlation between BMI and MUAC measurements ${ }^{(12,13,16)}$. The study by Dasgupta et al. documented that MUAC is highly sensitive $(97 \%)$ and specific ( $71 \%$ ) in the screening of malnourishment among adolescents (10-19 years) ${ }^{(13)}$. De Kankana $^{(13)}$ found that the mean MUAC was $21.7 \mathrm{~cm}$ and implied that BMI and MUAC have higher and significant correlation. MUAC can be a useful and efficient index for the screening of thinness, generally assessed from BMI. Gupta et $a l .{ }^{(15)}$ showed that the power of association between MUAC and BAZ $<-2$ was considerably high, and that MUAC can be a gold standard in assessment of thinness. They also found that MUAC $<18.5 \mathrm{~cm}$ was in agreement with $\mathrm{BAZ}<-2$ and MUAC cut-off of $<16.5 \mathrm{~cm}$ with $\mathrm{BAZ}<-3$. A survey conducted among 565 adolescent girls (16-18 years) from Pune, Maharashtra, warranted that MUAC had high specificity but low level of sensitivity ${ }^{(14)}$.

Third, our results show that the MUAC cut-off to detect thinness and severe thinness in young adolescent girls (10-14 years) was $\leq 19.4$ and $\leq 18.9 \mathrm{~cm}$, respectively, and it was $\leq 21.6$ and $\leq 20.7 \mathrm{~cm}$ for late adolescent girls (15-19 years). The specificity of the MUAC cut-off $(\leq 20.7 \mathrm{~cm})$ among 15-19-year-old adolescents for BAZ $<-3$ (93.1\%) was higher than the specificity of the MUAC cut-off $(\leq 21.6 \mathrm{~cm})$ for $\mathrm{BAZ}<-2(87.1 \%)$, signifying that MUAC can be more specific for diagnosis of thinness in a severely malnourished population. For both BAZ $<-2$ and $\mathrm{BAZ}<-3$, the specificity was higher for older adolescents (15-19 years) compared with younger adolescents (10-14 years; 75.4 and $87.1 \%$ for $\mathrm{BAZ}<-2 ; 74.1$ and $93.1 \%$ for $\mathrm{BAZ}<-3$ ), with sensitivity being similar for both. Hence, the MUAC cut-off is more specific for diagnosis of thinness in older adolescents, probably because they are fully grown, so there is less variation in the cut-offs. The results of the present study were corroborated by previous studies. Gupta et al. ${ }^{(15)}$ found that with BAZ $<-2$ as the gold standard, MUAC cut-off of $<18.5 \mathrm{~cm}$ had a sensitivity and specificity of 73 and $79 \%$, respectively, for detecting thinness in 10-19-year-old adolescent girls. In the same study, higher specificity (97.3\%) was obtained with $\mathrm{BAZ}<-3$ as the gold standard and MUAC cut-off of $<16 \mathrm{~cm}^{(15)}$. Another study reported similar findings on 10-19-year-old adolescent girls, with MUAC cut-off of $<22.9 \mathrm{~cm}$ showing a sensitivity of $53.4 \%$ and a much higher specificity of $79.9 \%{ }^{(13)}$. A survey conducted with 565 adolescent girls (16-18 years) from Pune, Maharashtra, also warranted that MUAC had high specificity $(96.5 \%)$ but low level of sensitivity $(28.5 \%)^{(14)}$. Thus, results indicate that MUAC has higher specificity and lower sensitivity, particularly for detecting thinness below the BAZ cut-off of -3 . It is, therefore, important to relate MUAC to age and sexual maturity of individual girls for a meaningful identification of thinness ${ }^{(23)}$, which was missed in the present study. From a programmatic perspective, it is not feasible to define a single MUAC cut-off to identify nutritionally at-risk adolescent girls between the ages of 10 and 19 years. 
Table 6 The burden of thinness and severe thinness based on mid-upper arm circumference (MUAC) and BMI-for-age Z-score (BAZ) among adolescent girls aged $10-19$ years ( $n$ 4628) from two eastern India states (Chhattisgarh and Odisha), October 2016-April 2017

\begin{tabular}{|c|c|c|c|c|c|c|}
\hline \multirow[b]{2}{*}{$\begin{array}{l}\text { Age } \\
\text { (years) }\end{array}$} & \multicolumn{3}{|c|}{ Thinness $(B A Z<-2)$} & \multicolumn{3}{|c|}{ Severe thinness $(B A Z<-3)$} \\
\hline & $\begin{array}{l}\text { MUAC cut-off } \\
(\mathrm{cm})\end{array}$ & $\begin{array}{l}\text { MUAC-based } \\
\text { prevalence (\%) }\end{array}$ & $\begin{array}{c}\text { BAZ-based } \\
\text { prevalence (\%) }\end{array}$ & $\begin{array}{l}\text { MUAC cut-off } \\
(\mathrm{cm})\end{array}$ & $\begin{array}{l}\text { MUAC-based } \\
\text { prevalence (\%) }\end{array}$ & $\begin{array}{c}\text { BAZ-based } \\
\text { prevalence (\%) }\end{array}$ \\
\hline 10 & $\leq 17.7$ & $41 \cdot 3$ & $19 \cdot 2$ & $\leq 17 \cdot 0$ & 9.6 & $2 \cdot 4$ \\
\hline 11 & $\leq 18.1$ & 52.8 & $20 \cdot 3$ & $\leq 17.6$ & $16 \cdot 4$ & $4 \cdot 1$ \\
\hline 12 & $\leq 19.0$ & $66 \cdot 2$ & 22.6 & $\leq 18.2$ & $22 \cdot 0$ & 4.5 \\
\hline 13 & $\leq 20.1$ & 43.0 & 12.9 & $\leq 18.8$ & $29 \cdot 3$ & 3.6 \\
\hline 14 & $\leq 20.6$ & 44.4 & 13.3 & $\leq 20.3$ & $15 \cdot 0$ & 3.5 \\
\hline 15 & $\leq 20.8$ & 57.5 & $10 \cdot 3$ & $\leq 20 \cdot 3$ & $30 \cdot 4$ & 2.9 \\
\hline 16 & $\leq 21.6$ & 35.1 & 7.5 & $\mathrm{NA}^{*}$ & NAt & 0.2 \\
\hline 17 & $\leq 21.7$ & $47 \cdot 8$ & 9.5 & $\leq 20.7$ & 11.5 & $2 \cdot 6$ \\
\hline 18 & $\leq 22 \cdot 3$ & 34.2 & $10 \cdot 6$ & $\leq 21 \cdot 1$ & 7.5 & 0.8 \\
\hline 19 & $\leq 22.5$ & 65.0 & $13 \cdot 7$ & $\leq 21.5$ & $20 \cdot 0$ & $3 \cdot 8$ \\
\hline $10-14$ & $\leq 19.4$ & $41 \cdot 3$ & $17 \cdot 1$ & $\leq 18.9$ & 11.0 & $3 \cdot 6$ \\
\hline $15-19$ & $\leq 21.6$ & $40 \cdot 0$ & 9.6 & $\leq 20.7$ & $17 \cdot 7$ & 1.7 \\
\hline
\end{tabular}

${ }^{*} \mathrm{NA}=$ cases insufficient to estimate a reliable MUAC cut-off for severe thinness.

†NA = cases insufficient to estimate a reliable MUAC cut-off for severe thinness. Hence, prevalence cannot be estimated.

Fourth, we found that with BAZ $<-2$ as the gold standard, the NPV was much higher than the PPV at all single-age MUAC cut-offs (PPV $=35-65 \%$, NPV > 95\%) signifying that the MUAC cut-offs were able to correctly exclude adolescents without thinness. Similar findings (NPV (>99\%) > PPV (10-30\%) at all cut-offs) were obtained with $\mathrm{BAZ}<-3$ as the gold standard. Thus, MUAC cut-offs were able to correctly exclude adolescents who were not thin according to BAZ. We also found that PPV was lower at MUAC cut-offs with $\mathrm{BAZ}<-3$ as the gold standard compared with MUAC cut-offs with BAZ $<-2$, while the NPV was higher. This is because, unlike sensitivity and specificity, predictive values are largely dependent on disease prevalence in the examined population. The prevalence of thinness would be much higher with the $\mathrm{BAZ}<-2$ cut-off than with the $\mathrm{BAZ}<-3$ cut-off $^{(17)}$. Hence the PPV was much higher at $\mathrm{BAZ}<-2$ than at BAZ $<-3$. However, PPV and NPV from one study should not be transferred to some other setting with a different prevalence of the disease in the population. Hence it is better to use SN and SP indicators for comparing results across different populations. There was no difference in the MUAC cut-offs, SN and SP values before and after adjusting for the outliers in the data.

Although our study identified both single-age MUAC cut-offs and cut-offs for younger (10-14 years) and older (15-19 years) adolescent girls, it is preferable to use single-age MUAC cut-offs due to wide variations in the cut-offs. For instance, the optimal MUAC cut-off to detect thinness $(\mathrm{BAZ}<-2)$ among adolescent girls aged 10-14 years was found to be $\leq 19.4 \mathrm{~cm}$, while the cut-off at 10 and 14 years was $\leq 17.7$ and $\leq 20.6 \mathrm{~cm}$, respectively, having a wide variation of $2.9 \mathrm{~cm}$. Thus, the chances of classifying a 10-year-old adolescent as thin is higher using the cut-off of $19.4 \mathrm{~cm}$ as compared with the single-age cut-off of $17.7 \mathrm{~cm}$. Hence, it is important that single-age MUAC cutoffs are used in field settings for identifying thinness among adolescents. However, in cases where the age of the adolescent is not known, the grouped cut-offs for younger and older adolescents can be used: MUAC $\leq 19.4 \mathrm{~cm}$ (10-14 years) and MUAC $\leq 21.6 \mathrm{~cm}$ (15-19 years). There are other considerations about what should be the nutrition support provided to adolescent girls with severe thinness, such as an extra meal or linkage with social protection, for which the assessment measure may be used to determine the response plan. This was outside the scope of the present paper, however it requires deliberation.

While MUAC is particularly useful in remote areas, where it is not possible to carry the weighing machine or stadiometer over long distances and so calculation of $\mathrm{BMI} / \mathrm{BAZ}$ is not feasible (hence MUAC tapes become handy in such places), there are some aspects of MUAC that should be kept in mind. First, MUAC changes substantially with age during adolescence, especially at the younger ages when growth patterns and physical maturity differ largely between individual girls. As a result, different cutoffs must be used for adolescents of different ages. This requires an accurate age for each survey subject in order to judge whether she falls above or below an age-specific cut-off. Second, despite the convenience and ease of measurement of MUAC, it requires careful training and supervision in order to prevent wrapping the measuring tape too tightly or too loosely, which results in an erroneous estimate and some degree of observer variability.

\section{Strengths and limitations}

The present community-based study was conducted on a reasonable sample size with good quality control and monitoring. The sample was drawn systematically from rural deprived areas where programmes and interventions to improve nutrition are intended. However, the following limitations merit consideration. Unlike previous studies, the current study has not defined one single MUAC 
cut-off to identify nutritionally at-risk adolescent girls between the ages of 10 and 19 years; rather single-age MUAC cut-offs were established for detection of thinness among adolescent girls. The study falls short in evaluating any health consequences and, therefore, cannot compare one method over another. The sample being selected from only two geographical areas is another limiting factor of the study, limiting generalizability of the results. Since we found differences in MUAC between the two states, we need large-scale data to arrive at national year-wise cut-offs for MUAC in Indian adolescents (both girls and boys) for appropriate interventions in emergency situations, field settings and outpatient therapeutic clinics as MUAC field charts. Moreover, since the sample was majorly drawn from poverty pockets in India, the analysis cannot be used to derive at MUAC cut-offs for overweight and obesity. Finally, the present study did not cover adolescent boys aged $10-19$ years.

\section{Conclusion}

To conclude, MUAC cut-off points with good predictive ability to detect thinness among adolescent girls aged 10-14 years (young adolescents) and 15-19 years (late adolescents) were $\leq 19.4$ and $\leq 21.6 \mathrm{~cm}$, respectively. The age-wise, sex-wise and context-specific MUAC cut-offs should be preferred in place of one MUAC cut-off across 10-19 years, based upon several considerations including purpose, burden and logistic resources. Availability of MUAC field charts by year, for adolescent boys and girls, by context/region, will prove useful in settings where BAZ/BMI is not available. However, prior evidence from large-scale representative survey data wherein MUAC and BAZ measurements have been taken for adolescents is needed to prove/disprove MUAC diagnostic accuracy and suitability for the specific region/context compared with BAZ.

\section{Acknowledgements}

Acknowledgements: The authors would like to thank Dr Neha Sareen and Dr H.P.S. Sachdev for review and editing support of preliminary drafts. Financial support: This work was supported by UNICEF, India. V.S. and A.d.W. are employed by UNICEF. However, the views expressed are those of authors and not necessarily those of UNICEF. Conflict of interest: None. Author contribution: V.S. and S.U. conceptualized and supervised the study. N.G. wrote the manuscript and revised it critically. S.P., A.S., K.D.S. and H.U.R. coordinated the data collection and entry and carried out data analysis. A.d.W. and V.S. reviewed and supported additional analyses and revised the manuscript critically. All authors reviewed the manuscript and have approved the final version. Ethics of human subject participation: This study was conducted according to the guidelines laid down in the Declaration of Helsinki and all procedures involving human subjects were approved by the Institutional Ethics Committee of the All India Institute of Medical Sciences (AIIMS), Chhattisgarh and AIIMS, Odisha. Written informed consent was obtained from all subjects. The impact evaluation has been registered with the Registry for International Development Impact Evaluations (RIDIE-STUDY-ID-58261b2f46876) and the Indian Council of Medical Research (ICMR) National Clinical Trials Registry of India (CTRI/2016/11/007482).

\section{References}

1. World Health Organization (2007) Growth reference 5-19 years: BMI-for-age (5-19 years). http://www.who.int/ growthref/who2007_bmi_for_age/en/ (accessed March 2019).

2. World Health Organization (2011) IMAI District Clinician Manual: Hospital Care for Adolescents and Adults. Guidelines for the Management of Illnesses with Limited Resources. Geneva: WHO.

3. The Republic of South Sudan (2017) Community Management of Acute Malnutrition: CMAM Guidelines. https://reliefweb.int/sites/reliefweb.int/files/resources/cmam_ guidelines_book.pdf (accessed October 2018).

4. UNICEF (2010) Somali Guidelines for Management of Acute Malnutrition. https://www.humanitarianresponse.info/sites/ www.humanitarianresponse.info/files/Guideline\%2520for $\% 2520$ Integrated $\% 2520$ management $\% 2520$ of $\% 2520$ Acute $\% 2520$ Malnutrition.pdf (accessed October 2018).

5. Ethiopia Federal Ministry of Health (2007) Protocol for the Management of Severe Acute Malnutrition. http:// motherchildnutrition.org/resources/pdf/mcn-ethiopia-samguidelines.pdf (accessed October 2018).

6. Bahwere P (2017) Anthropometric cut-off points for older children and adolescents in Syria. Field Exch $\mathbf{5 4}, 44$.

7. Martin AC, Pascoe EM \& Forbes DA (2009) Monitoring nutritional status accurately and reliably in adolescents with anorexia nervosa. J Paediatr Child Health $\mathbf{4 5}$, $53-57$.

8. Ministry of Health and Family Welfare (2017) Guidance Document: Nutrition Care and Support for Patients with Tuberculosis in India. https://tbcindia.gov.in/WriteReadData/ Guidance\%20Document\%20-\%20Nutritional\%20Care\%20\% $26 \% 20$ Support $\% 20$ for $\% 20 \mathrm{~TB} \% 20$ patients\%20in\%20India.pdf (accessed June 2018).

9. Food and Nutrition Technical Assistance Project (2018) Anthropometry: children and adolescents 5-19 years. https://www.fantaproject.org/sites/default/files/resources/ FANTA-Anthropometry-Children-Adolescents-5-19-Jun2018. pdf (accessed October 2018).

10. UNICEF (2018) Forging an anaemia-free future. Scaling up India's Integrated Adolescent Girls' Anaemia Control Programme. https://anemiamuktbharat.info/portal/wp-content/ uploads/2018/09/Field_report_nutrition-web3.pdf (accessed October 2018).

11. Ministry of Health and Family Welfare (2014) Rashtriya Kishor Swasthya Karyakram. Operational framework, translating strategy into programmes. http://nhm.gov.in/images/ pdf/programmes/RKSK/RKSK_Operational_Framework.pdf (accessed October 2018).

12. Dasgupta A, Butt A, Saha TK et al. (2010) Assessment of malnutrition among adolescents: can BMI be replaced by MUAC. Indian J Community Med 35, 276-279. 
13. De K (2016) Assessment of nutritional status of adolescent girls by mid-upper arm circumferences of Paschim Medinipur, India. Primary Health Care 6, 4.

14. Jeyakumar A, Ghugre P \& Gadhave S (2013) Mid-upper-arm circumference (MUAC) as a simple measure to assess the nutritional status of adolescent girls as compared with BMI. Infant Child Adolesc Nutr 5, 22-25.

15. Gupta P, Kondal D, Mebrahtu S et al. (2016) Diagnostic accuracy of mid-upper-arm-circumference for screening thinness in Indian adolescents. Abstract: Micronutrient Forum. http://micronutrientforum.org/abstracts/diagnosticaccuracy-of-mid-upper-arm-circumference-for-screeningthinness-in-indian-adolescents/ (accessed June 2018).

16. Registry for International Development Impact Evaluations (2018) Integrated multisectoral strategy to improve girls' and women's nutrition before conception, during pregnancy and after birth in India (Swabhimaan): prospective, non-randomised controlled evaluation. Study ID: RIDIESTUDY-ID-58261b2f46876. http://ridie.3ieimpact.org/index. php? $\mathrm{r}=$ search/detailView\&id=485 (accessed June 2018).

17. Ulijaszek SJ \& Kerr DA (1999) Anthropometric measurement error and the assessment of nutritional status. BrJ Nutr $\mathbf{8 2}$, 165-177.
18. World Health Organization (1995) Physical Status: The Use and Interpretation of Anthropometry. Report of a WHO Expert Committee. WHO Technical Report Series no. 854. Geneva: WHO.

19. Kumar R \& Indrayan A (2011) Receiver operating characteristic (ROC) curve for medical researchers. Indian Pediatr $\mathbf{4 8}$, 277-287.

20. NCSS Statistical Software (2016) One ROC Curve and Cutoff Analysis. https://ncss-wpengine.netdna-ssl.com/wp-content/ themes/ncss/pdf/Procedures/NCSS/One_ROC_Curve_and_ Cutoff_Analysis.pdf (accessed March 2018).

21. Schisterman EF, Perkins NJ, Liu A et al. (2005) Optimal cutpoint and its corresponding Youden Index to discriminate individuals using pooled blood samples. Epidemiology 16, 73-81.

22. Unal I (2017) Defining an optimal cut-point value in ROC analysis: an alternative approach. Comput Math Methods Med 2017, 3762651.

23. Tang AM, Dong K, Deitchler M et al. (2013) Use of Cutoffs for Mid-Upper Arm Circumference (MUAC) As an Indicator or Predictor of Nutritional and Health-Related Outcomes in Adolescents and Adults: A Systematic Review. Washington, DC: FHI 360/FANTA. 